that PlGF, a homolog of VEGF, affects angiogenesis in disease but not in health. The implication of these findings is that blocking PlGF might combine efficacy in inhibiting tumor growth with safety of only affecting tumor but not quiescent vessels. Conversely, delivery of PlGF stimulated revascularization of ischemic tissues. Our studies also showed that low levels of VEGF cause motor neuron degeneration, reminiscent of ALS. We have now demonstrated that VEGF prolongs survival in ALS rodent models. Clinical trials are underway.

$J C I$ : What is the biggest challenge you face?

Collen: To secure a steady flow of funding and talented researchers to compete at the front line of basic research and to efficiently transfer technology for potential medical applications to interested industrial partners.

Carmeliet: Understanding the molecular basis of angiogenesis and lymphangiogenesis, using mouse, zebrafish, and frog genetic models. Our focus is evolving from identifying which signals stimulate endothelial cells to migrate and divide, to understanding how blood vessels, lymph vessels, and neurons navigate to their targets. Our discovery that VEGF has neurotrophic effects in animal models of ALS may indicate a new approach to treatment of this and other lifethreatening neurodegenerative disorders. A challenge will be to initiate clinical trials, evaluating the therapeutic potential of VEGF for ALS.

JCI: In a typical day, how much of your time do you spend in the lab involved in research?

Collen: I am primarily involved in the overall coordination of the research programs of approximately 160 investigators and technical staff. Much of my time is devoted to drug development programs spun out of the laboratory into dedicated spin-offs. I primarily focus on drug development and technology transfer issues.

Carmeliet: Apart from some teaching and administrative duties, I, together with 4 other senior associates, spend my entire time supervising and coaching a research team of 55 postdocs, PhD students, and technicians. I am primarily involved in the conception of projects, writing grants and papers, and managing and coordinating the mouse, zebrafish, and frog facilities.

JCI: What do you think is the most important discovery you have ever made?

Collen: The molecular regulation of physiological fibrinolysis (breaking down blood clots) and its application to fibrin-relative thrombolytic therapy of acute myocardial infarction.

Carmeliet: Three discoveries seem most relevant: the critical role of VEGF in vascular development and disorders; the finding that PlGF is involved in angiogenesis in disease but not in health, and that PIGF stimulates revascularization of ischemic tissues, while PlGF blockers inhibit pathological angiogenesis; the finding that VEGF is a key survival factor for motor neurons in ALS and that VEGF prolongs survival of ALS rodents.

$J C I$ : What is your ultimate scientific goal?

Collen and Carmeliet: Understanding the molecular mechanisms governing cardiovascular and nervous system function, and the development of mechanism-based novel treatments for life-threatening cardiovascular and neurological diseases.

\section{Stacie Bloom}

\title{
In the debate of sex and science, Summers, Hopkins, and the X chromosome battle it out
}

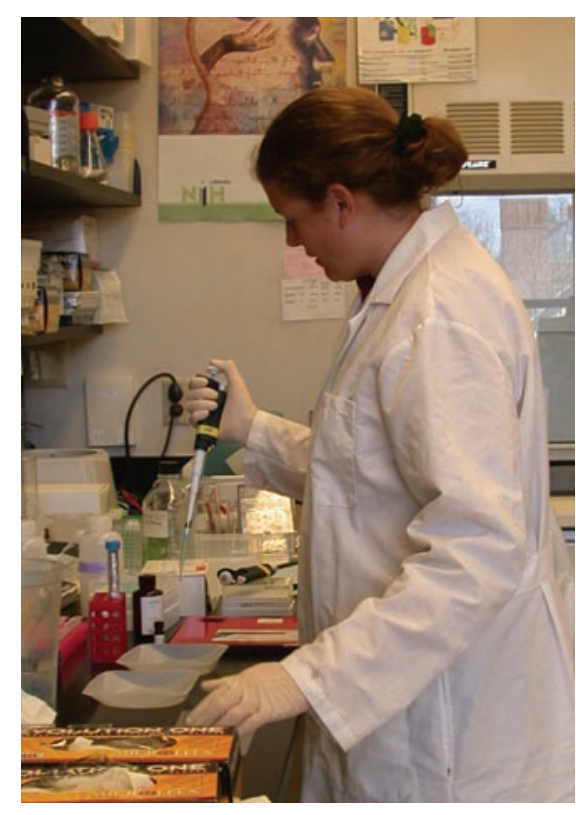

W ence on January 14,2005, Lawrence Summers, the president of Harvard University, suggested that innate biological differences between men and women might be one reason for the paucity of women math and science professors. Nancy Hopkins, a biology professor at the Massachusetts Institute of Technology (MIT), walked out upon hearing this remark. Both Summers' comments and Hopkins' reaction have received significant publicity and undergone much scrutiny.

Hopkins is an accomplished molecular biologist, but it is her pioneering role in

Women are still underrepresented in science, but are unintentional gender biases or innate biological differences to blame? Photo courtesy of Kate Prybylowski (NIH, Bethesda, Maryland, USA). fostering gender equity in academia for which many have come to know her. At the start of her career, Hopkins assumed that so few women worked in science because they wanted families and thus opted out of the 80-hour work week she associated with a successful career in the lab. Hopkins herself married young, but was divorced by 30 and decided not to have children. Early on, Hopkins repeatedly observed men and women equally accomplished in the lab, but noticed that they were not treated the same by colleagues. She did not see women as chairmen or as speakers, nor did she see women faculty with administrative power.

Hopkins says she was in denial about the situation and just worked harder until one particular event, 20 years into her career, opened her eyes. When she needed 
an additional 200 square feet of lab space, Hopkins started measuring nearby labs with a tape measure and realized that, as a full professor, she had much less space than her male counterparts and also lacked the power to get what she needed. She set out to remedy the situation.

In 1995, Hopkins was appointed chair of the first Committee on Women Faculty in the School of Science at MIT. At the time, there were 194 male faculty in the school, compared with 17 female. An extensive investigation by the committee was released in 1999 and sparked a flurry of attention when it was published in the Boston Globe and the New York Times. The committee found that women faculty tended to leave after tenure because they felt they were not part of the system in the same way as their male colleagues. The women tended to work alone, were not part of group grants, and were not in administrative positions. Interestingly, half of the women were unmarried without children, while nearly all their male counterparts had families. The committee concluded that MIT was experiencing unintentional gender bias.

MIT responded by recruiting more women faculty, both to the university and to administrative positions. The university established gender equity committees chaired by senior female faculty to review salary data and interview the faculty. The president also established a Council on Faculty Diversity, which establishes institutional policies regarding such issues as hiring and family leave. Altogether, MIT created 11 committees to infiltrate the university structure. As a result, and in only 6 years, the number of women science faculty has nearly doubled, while the number of women faculty in engineering has undergone an almost 5-fold increase. MIT has become a model for recognizing, acknowledging, and rectifying gender bias.

On March 25, 2005, Hopkins gave her first talk since the now-infamous Summers comment. Hopkins said she felt "like we turned the clock back 40 years" when Summers said that innate aptitude differences between men and women may be to blame for the dearth of women engineers, scientists, and mathematicians in advanced faculty positions. She said she "couldn't sit there and take it" and "that it was morally wrong to listen" to Summers's dismissal of the existence of gender discrimination after all the research that she and others had done. In reference to Rosalind Franklin, Hopkins joked, "If you discover the structure of DNA, you win the Nobel prize, right? Well, depends who you are."

Hopkins's response to Summers is timely in light of a study recently published in Nature, which examines the complete sequence of the $\mathrm{X}$ chromosome (1). A companion paper in the same issue (2) shows that the second $\mathrm{X}$ chromosome - found only in women and thought to be silent - actually expresses many genes. Interestingly, different women express different genes from this "silent" chromosome, and do so at different levels. The two papers explain why men and women are biologically different, and why women are different from each other. The papers do not, however, lend any credence to the concept that innate aptitude differences exist between the sexes.

\footnotetext{
1. Ross, M.T., et al. 2005. The DNA sequence of the human X chromosome. Nature. 434:325-337.

2. Carrel, L., and Willard, H.F. 2005. X-inactivation profile reveals extensive variability in X-linked gene expression in females. Nature. 434:400-404
}

\section{Stacie Bloom}

\section{PETA continues to claw at Columbia scientists}

$P$ been aggressively campaigning for animal rights since its inception in 1980, when its undercover investigation of a Maryland primate laboratory exposed numerous abuses. This investigation resulted in the first-ever conviction of animal researchers and the first US Supreme Court victory for laboratory animals. Today, with over 800,000 members, PETA is the world's largest animal rights support group. The group broadcasts its continuing struggle against laboratory animal abuse with very public, eye-catching, and provocative campaigns. One long-standing and dogged movement is directed against animal research at Columbia University.

According to the federal Animal Welfare Act, an estimated 23 million mammals, from rodents to primates, have been killed in laboratory studies. The targets of recent PETA condemnation are Columbia University professors Michel Ferin and Raymond Stark, and assistant professor E. Sander Connolly, who use such mammals in their experiments. Connolly studies brain damage resulting from strokes, and has been successful in elucidating new neuroprotective mechanisms and therapeutic strategies in mice and baboons.

Although Columbia University sanctioned Connolly's project in March 2000, PETA continues to release a firestorm of criticism and movement against the practice of clinical testing and against Columbia University in particular. PETA maintains a website dedicated entirely to the university (http://www. columbiacruelty.com), which reports offenses on the part of researchers and refers to Ferin, Stark, and Connolly as "Columbia's Death Squad." Unafraid to use words like "grotesque" and "horrifying," PETA juxtaposes films of alleged abuse with calls for action "to end the cruel and crude experiments, which have no practical value."

An in-house investigation into Connolly's experiments, spurred by a former Columbia University veterinarian and PETA informant, was ordered by the university in early 2003, and has thus far found no evidence of any significant violations of conduct. For now, Connolly himself has halted the studies until the formal investigation is complete. PETA, meanwhile, updates its Columbia-centric website with current developments and celebrity endorsements and urges support from the public. Of course, animal testing has not ceased, so research scientists and PETA continue to wrangle. While many researchers consider animal research to be necessary, PETA considers it murder.

Rick Ring and Stacie Bloom 